\title{
Comments on Conceptualizing and Measuring the Exchange of Beauty and Status
}

Aaron Gullickson

University of Oregon

aarong@uoregon.edu

\begin{abstract}
In this comment, I identify two methodological issues in McClintock's (2014) article on beauty exchange. First, McClintock's difference models, which find no evidence of exchange, are poor measures of exchange that fail to account for important confounders and rely on an overly narrow conceptualization of exchange. Second, McClintock codes her log-linear models to find a difference in the effect of men's and women's beauty in exchange rather than the total effect of women's beauty, which is both statistically significant and substantively large.
\end{abstract}

Sociologists have long been interested in the role of exchange in romantic partnering. Exchange theory posits that partners trade desirable resources with one another to create a match appealing to both partners. This exchange perspective can help reveal the implicit valuations attached to different kinds of partner characteristics. For example, evidence of exchange of racial status for education in black/white marriages demonstrates the unequal access that blacks have to potential white partners and the devaluing of blackness in partner selection (Fu 2001;

Gullickson 2006; Gullickson and Torche 2014). Much empirical work (and debate) on exchange focuses on the case of interracial marriage, but the idea of the "trophy wife," in which an attractive woman of modest means marries a wealthy, but less attractive, man, is a far more common and popular conception of exchange. In this case, one partner's attractiveness is exchanged for another partner's social status (e.g., wealth, prestige). It is popularly thought that in such exchanges, women's beauty and men's money matters more than vice versa.

Prior work has found evidence of beauty exchange (Carmalt et al. 2008; Elder 1969; Taylor and Glenn 1976; Udry 1977), but in a recent $A S R$ article, Elizabeth McClintock critiques this prior work on methodological grounds (McClintock 2014). Based on data from the National Survey of Adolescent Health on young dating, cohabiting, and married partners, McClintock finds weak evidence that beauty is exchanged for other kinds of desirable partner characteristics, measured primarily by education. McClintock has done a service to the discipline by clearly demonstrating the methodological shortcomings of prior work and pushing empirical research forward with new data and analyses. However, as I will show, some of McClintock's own models suffer from methodological shortcomings that tend to understate the evidence of beauty exchange. My goal in this comment is to illustrate these shortcomings to help move the field forward in terms of conceptualizing and measuring exchange.

Researchers have frequently looked at the simple correlation between one (ego) partner's attractiveness and the other partner's status. McClintock correctly critiques this approach because it does not account for the other partner's attractiveness and the ego partner's status. Partners tend to match on attractiveness, and attractiveness is positively associated with status characteristics such as education. Therefore, the positive association between one partner's attractiveness and the other partner's status may simply reflect that partners tend to match on attractiveness, and attractiveness is associated with having higher status for both partners.

McClintock uses three different approaches to remedy this problem. First, McClintock uses conventional regression models to estimate the correlation between ego partner's status and the other partner's attractiveness, controlling for the ego partner's attractiveness and the other partner's status. Second, McClintock estimates the correlation between the difference in partner 
attractiveness and the difference in partner status. Third, McClintock estimates log-linear models that examine whether unions that are consistent with a pattern of exchange are more frequent than one would expect by random chance. For the conventional regression models and the log-linear models, McClintock also separates her estimates into a "gender stereotypical" effect that measures the trading of women's beauty for men's status, and a "reverse stereotypical" effect that measures the trading of men's beauty for women's status.

For each model, McClintock uses three different measures of status. The first measure is completed years of education. The second is expected college graduation, which includes individuals who have a four-year college degree or are currently enrolled in a four-year college degree program. The third is a forecast measure of Duncan's Socioeconomic Index (SEI) based on race, age, educational attainment, current SEI, picture-vocabulary test scores, parental income, parental education, and parental SEI. To illustrate the modeling issues, I focus on the straightforward measure of completed years of education. For this measure of status, McClintock finds evidence of exchange in the conventional regression models, no evidence of exchange in the difference models, and some inconclusive evidence of exchange in the loglinear models. Overall, the results do not seem to strongly support a finding of exchange between completed years of education and beauty.

However, some of these models are problematic for properly measuring exchange. First, from both a methodological and a theoretical point of view, the difference model is a poor measure of exchange. When its shortcomings are corrected, the difference model turns out to be identical to the conventional regression model. The second issue is that rather than report the total effect of exchange for women in the log-linear models, McClintock uses interaction-style coding to split this total effect into two parts, and she misinterprets the results as suggesting an equivocal finding for gender-stereotypical exchange, when in fact the results unequivocally support a gender-stereotypical exchange effect.

\section{THE PROBLEM WITH DIFFERENCE MODELS}

I begin by showing the algebraic relationship between McClintock's conventional regression model and the difference model. Focusing on the male's education (educ), the conventional regression model has the following form:

$$
\left.\left.\left.(\text { male educ })=b_{0}+b_{1} \text { (female beauty }\right)+b_{2} \text { (male beauty }\right)+b_{3} \text { (female educ }\right)
$$

The key coefficient in this model is $b_{1}$, which gives the expected increase in a male partner's years of education when the female partner is one unit higher on the attractiveness scale, holding constant the male's own beauty and the female's own education. The controls for male beauty and female education are important for eliminating the confounding effects that McClintock criticizes prior work for neglecting.

The difference model is given by the following:

$$
\left.(\text { male educ }- \text { female educ })=g_{0}+g_{1} \text { (male beauty }- \text { female beauty }\right)
$$

McClintock argues that if partners are trading one resource for another, such a tradeoff implies that one partner will have a higher value on one resource and the other partner will have a higher value on the other resource. Therefore, the correlation between these differences in resources should be negative, and thus $g_{1}$ should be negative.

In Table 1, I replicate the conventional regression model and difference model from McClintock's article. My models leave out irrelevant methodological complications, but they 
produce substantively identical conclusions. ${ }^{1}$ My conventional regression model finds a strong positive effect of female attractiveness on male education, holding constant male attractiveness and female education, and my difference model finds a substantively small and statistically insignificant effect.

\section{$<$ Table 1 about here $>$}

Given this discrepancy in results between the conventional model and the difference model, McClintock (2014:590) preferred the latter model as the "most direct and compelling test," presumably because she believes it directly measures the tradeoff in partner characteristics. However, the difference model is a poor test of exchange on two grounds. First, on a methodological level, the difference model is nothing more than a constrained version of the conventional regression model without the necessary controls to effectively test for exchange. Second, the belief in an absolute tradeoff between spouses is an overly narrow conceptualization of exchange.

The methodological issue can be shown by using algebraic manipulation to isolate male education on the left-hand side of the difference model (Equation 2):

$$
\left.(\text { male educ })=g_{0}-g_{1}(\text { female beauty })+g_{1} \text { (male beauty }\right)+(1)(\text { female educ })
$$

This model is now identical in form to the conventional regression model except it makes implicit assumptions about the effects of male beauty and female education on male education ( $b_{1}=-g_{1}$ and $b_{3}=1$, respectively). These assumptions can be directly tested in the data by explicitly including female education and male attractiveness as control variables in the difference model, as shown in the third column of Table 1. If the implicit assumptions are true, then these additional parameters should be zero, but these tests are both strongly rejected. The difference model fits the data poorly, relative to the conventional regression model.

Once these controls are added to the difference model, it is identical to the conventional regression model. As Table 1 shows, the coefficient for attractiveness difference is now strongly negative and identical in absolute magnitude to the result for the conventional regression model. Furthermore, the other two terms in this model are directly derivable from the conventional regression model $(-.458=.542-1$ and $.173+.194=.367)$.

Why does the difference model without controls produce such different results? Because more attractive individuals also tend to have more education, they are less likely to find available partners with whom they can trade up on one characteristic while trading down on the other. The same is true at the low end of the education and attractiveness distributions, for opposite reasons. This effect can be seen in Table 2, which shows the correlation matrix between all four variables in the models as well as the differences in education and attractiveness. Men's education is strongly positively correlated with the education difference, men's attractiveness is strongly positively correlated with the attractiveness difference, and there are similarly strong negative correlations for women. This is because of mechanical ceiling/floor effects, respectively. For example, highly educated men have fewer opportunities to marry women less educated than themselves, and less educated women have more opportunities to marry men more educated than themselves. Because education and attractiveness are correlated both within and between partners, these ceiling/floor effects become confounded with the basic correlation between the two difference measures. The only way to account for these ceiling/floor effects is to control for one partner's education and the other partner's attractiveness, which leads one back to a conventional regression model.

$<$ Table 2 about here $>$ 
The explanation above highlights that the key issue with the difference model is the way in which it conceptualizes exchange. The notion of an absolute tradeoff in which each spouse has more of something is a popular and intuitively seductive, but overly narrow, way to conceptualize exchange. Exchange simply implies that a person with a relatively high value on one desirable characteristic, compared to other competing suitors, will be able to attract a partner who has a relatively high value on another desirable characteristic, compared to other potential mates. The key issue here is the relative value of the characteristic compared to other potential partners, rather than its absolute value. The conventional model captures this broader sense of exchange in terms of the correlation between partner characteristics (holding confounders constant), but the difference model does not.

\section{LOG-LINEAR MODEL INTERPRETATION}

McClintock codes a single term in the log-linear models to test beauty exchange. This term gives the ratio of the odds (on the log scale) of a person who is rated as more attractive than their partner marrying upward in terms of education relative to the same odds for a person who is as attractive or less attractive than their partner. A positive term is seen as evidence of exchange. McClintock tests two versions of this model. First, McClintock tests a "gender symmetric" version in which the effects of beauty on education are assumed to be the same for men and women; she then estimates a model that allows for a different effect depending on whether the estimate refers to the exchange effect of beauty for women (gender stereotypical exchange) or men (reverse stereotypical exchange).

Table 3 shows my replication of McClintock's model for education in the first two columns (Models $1 \mathrm{a}$ and $1 \mathrm{~b}$ from the original article). My results match McClintock's numbers from her Table 7 exactly. The gender symmetric results in Model 1a provide substantial and statistically significant evidence of exchange. The odds of an upward educational union for a partner who is judged more attractive than the other partner are 68 percent higher than the odds of an upward educational union for a partner who is judged to be as attractive or less attractive than their partner. However, when the effects are split by gender in Model $1 \mathrm{~b}$, in the same manner as McClintock, the statistically significant result seems to go away and the magnitude of both effects is smaller than the gender symmetric effect. Based on these results, McClintock (2014:593) writes that "there is no evidence of gender-stereotypical exchange — women are not significantly more likely to trade attractiveness for status than are men."

\section{$<$ Table 3 about here $>$}

However, McClintock does not directly estimate the gender-stereotypical effect of women's attractiveness in Model 1b. McClintock coded her variables in the style of an interaction term such that what is labeled a "gender-symmetric exchange" effect is the main effect that both gender-stereotypical and reverse-stereotypical couples receive, and what is labeled "genderstereotypical exchange" is the difference in effects between gender-stereotypical and reversestereotypical exchange. If the goal is to estimate the total effect of gender-stereotypical exchange, one needs to add together the main effect and the interaction term. Alternatively, one can simply estimate two entirely separate main effects, as I did in Model 1c of Table 3 . The total effect for women is .689 and is strongly statistically significant. The estimate indicates that when a woman is judged more attractive than her male partner, the odds of an upward educational union are about double the odds for a woman who is judged to be as attractive or less attractive than her male partner.

Figure 1 illustrates the issue. In the gender-symmetric model, a single term is fit which is found to be statistically significant. In the second model, this term is estimated separately for men and 
women, but instead of estimating two separate main effects as identified by (a) and (b), McClintock estimates the main effect for the smaller of the two effects (a) and the difference in effect (i.e., interaction term) between (a) and (b) as measured by (c).

\section{$<$ Figure 1 about here $>$}

In light of these issues, McClintock's (2014:593) claim that "there is no evidence of genderstereotypical exchange-women are not significantly more likely to trade attractiveness for status than are men" is partially incorrect. The dash suggests that the second statement is a clarification of the first statement, but the two statements are making two different claims. The first statement is false given the results of the models - the evidence of gender-stereotypical exchange in the case of years of education (effect [b] from Figure 1) is strong. The second statement is consistent with the results but is incomplete (effect [c] from Figure 1). Using the logic of null hypothesis significance testing, one cannot confidently claim that women are more likely than men to trade beauty for status, but one also cannot claim confidently that men trade beauty for status at all. The results for men's beauty are equivocal, the results for women's beauty are not.

\section{CONCLUSIONS}

The thoroughness of McClintock's analysis is commendable. Rather than rely on a single model with a single measure of status, McClintock uses three different model specifications on three different measures of status to test for the existence of beauty exchange. Such robustness checks are a useful tool. However, when different models produce different results, scholars need to understand why such discrepancies exist. In this case, the discrepancy between the conventional regression models and difference models used by McClintock is driven by the failure of difference models to account for important confounders that are accounted for by the conventional models. More critically, the difference models use a narrow conceptualization of exchange that insists on an absolute tradeoff among partners. My hope in this comment is to dissuade future researchers from using such flawed models; instead, one should rely on either the conventional regression model or log-linear models to capture the effect of exchange. In addition, McClintock's interpretation of the results of the log-linear models downplays the importance of exchange by failing to directly estimate the exchange effect of women's beauty.

Taking these issues into consideration, should we reconsider McClintock's claim that there is little evidence of beauty exchange? When the measure of status is years of education, substantial evidence of exchange is found for both the regression and log-linear models. However, more equivocal results are found for both models when expected college graduation and forecast SEI are used as measures of status. Upon re-evaluation, McClintock's results should be seen as somewhat inconclusive in demonstrating the existence of beauty exchange rather than as a knockout blow for either its effect or lack of effect. 


\section{Data Note}

Full code and log files for the analysis in this comment are available at https://github.com/AaronGullickson/beautyexchange. Due to privacy restrictions on Add Health data, the data are not re-distributable.

\section{Acknowledgments}

I would like to thank Florencia Torche and several anonymous reviewers for providing helpful feedback on the statistical models used here. Any errors are entirely the author's own.

\section{Note}

1. There are three sources of difference between my models and McClintock's. First, I do not standardize the quantitative variables because this has no meaningful impact on the outcome. Second, I do not include control variables, because the issue I identify here is true regardless of the number of control variables introduced. Third, I do not use multiple imputation for missing values, because only one value of education is missing across all observations and no values of attractiveness are missing.

\section{References}

Carmalt, Julie H., John Cawley, Kara Joyner, and Jeffery Sobal. 2008. "Body Weight and Matching with a Physically Attractive Romantic Partner." Journal of Marriage and Family 70(5):1287-96.

Elder, Glen H. 1969. “Appearance and Education in Marriage Mobility.” American Sociological Review 34(4):519-33.

Fu, Vincent K. 2001. “Racial Intermarriage Pairings.” Demography 38(2):147-59.

Gullickson, Aaron. 2006. "Education and Black-White Interracial Marriage.” Demography 43(4):673-89.

Gullickson, Aaron, and Florencia Torche. 2014. "Patterns of Racial and Educational Assortative Mating in Brazil.” Demography 51(3):835-56.

McClintock, Elizabeth A. 2014. "Beauty and Status: The Illusion of Exchange in Partner Selection?" American Sociological Review 79(4):575-604.

Taylor, Patricia Ann, and Norval D. Glenn. 1976. "The Utility of Education and Attractiveness for Females' Status Attainment through Marriage.” American Sociological Review 41(3):48498.

Udry, J. Richard. 1977. "The Importance of Being Beautiful: A Reexamination and Racial Comparison.” American Journal of Sociology 83(1):154-60. 
Table 1. Results from Regression Models Predicting Male Partner's Education (Conventional) and the Difference between Male and Female Partners' Education

\begin{tabular}{llll}
\hline Variables & Conventional Model & Difference Model & \multicolumn{1}{c}{$\begin{array}{c}\text { Difference Model with } \\
\text { Controls }\end{array}$} \\
\hline Attractiveness difference & & $-.031 \quad\left(g_{1}\right)$ & $-.173^{* * *}\left(-1 \times b_{1}\right)$ \\
& & $(.049)$ & $(.051)$ \\
Female attractiveness & $.173^{* * *}\left(b_{1}\right)$ & & \\
& $(.051)$ & & $.367 * * *\left(b_{1}+b_{2}\right)$ \\
Male attractiveness & $.194 * * *\left(b_{2}\right)$ & & $(.068)$ \\
Female education & $(.059)$ & & $-.458^{* * *}\left(b_{3}-1\right)$ \\
& $.542^{* * *}\left(b_{3}\right)$ & $(.021)$ & $(.022)$ \\
\hline
\end{tabular}

Note: Standard errors are in parentheses. Letters refer to Equations 1 and 2 from the text.

$* p<.05 ; * *<.01 ; * * * p<.001$ (two-tailed tests).

Table 2. Correlation Matrix between Partner Attractiveness, Years Education, and Partner Differences in Both Variables

\begin{tabular}{lccccc}
\hline & $\begin{array}{c}\text { Male }- \text { Female } \\
\text { Education }\end{array}$ & $\begin{array}{c}\text { Male }- \text { Female } \\
\text { Attractiveness }\end{array}$ & $\begin{array}{c}\text { Male } \\
\text { Education }\end{array}$ & $\begin{array}{c}\text { Female } \\
\text { Education }\end{array}$ & $\begin{array}{c}\text { Male } \\
\text { Attractiveness }\end{array}$ \\
\hline Male - female attractiveness & -.017 & & & & \\
Male education & .481 & -.056 & & & \\
Female education & -.463 & .010 & .555 & & \\
Male attractiveness & .032 & .544 & .165 & .137 & .247 \\
Female attractiveness & .047 & -.678 & .151 & .108 & .247 \\
\hline
\end{tabular}

Table 3. Estimate of Beauty Exchange Term from Log-Linear Models

\begin{tabular}{|c|c|c|c|}
\hline Beauty Exchange Term & Model 1a & Model 1b & Model 1c \\
\hline Gender Symmetric & $\begin{array}{c}.524 * * * \\
(.155)\end{array}$ & & \\
\hline Men & & $\begin{array}{l}.342 \\
(.219)\end{array}$ & $\begin{array}{l}.342 \\
(.219)\end{array}$ \\
\hline Difference (women vs. men) & & $\begin{array}{c}.347 \\
(.295)\end{array}$ & \\
\hline Women & & & $\begin{array}{l}.689 * * \\
(.210) \\
\end{array}$ \\
\hline
\end{tabular}

Note: Standard errors are in parentheses.

$* p<.05 ; * * p<.01 ; * * * p<.001$ (two-tailed tests). 

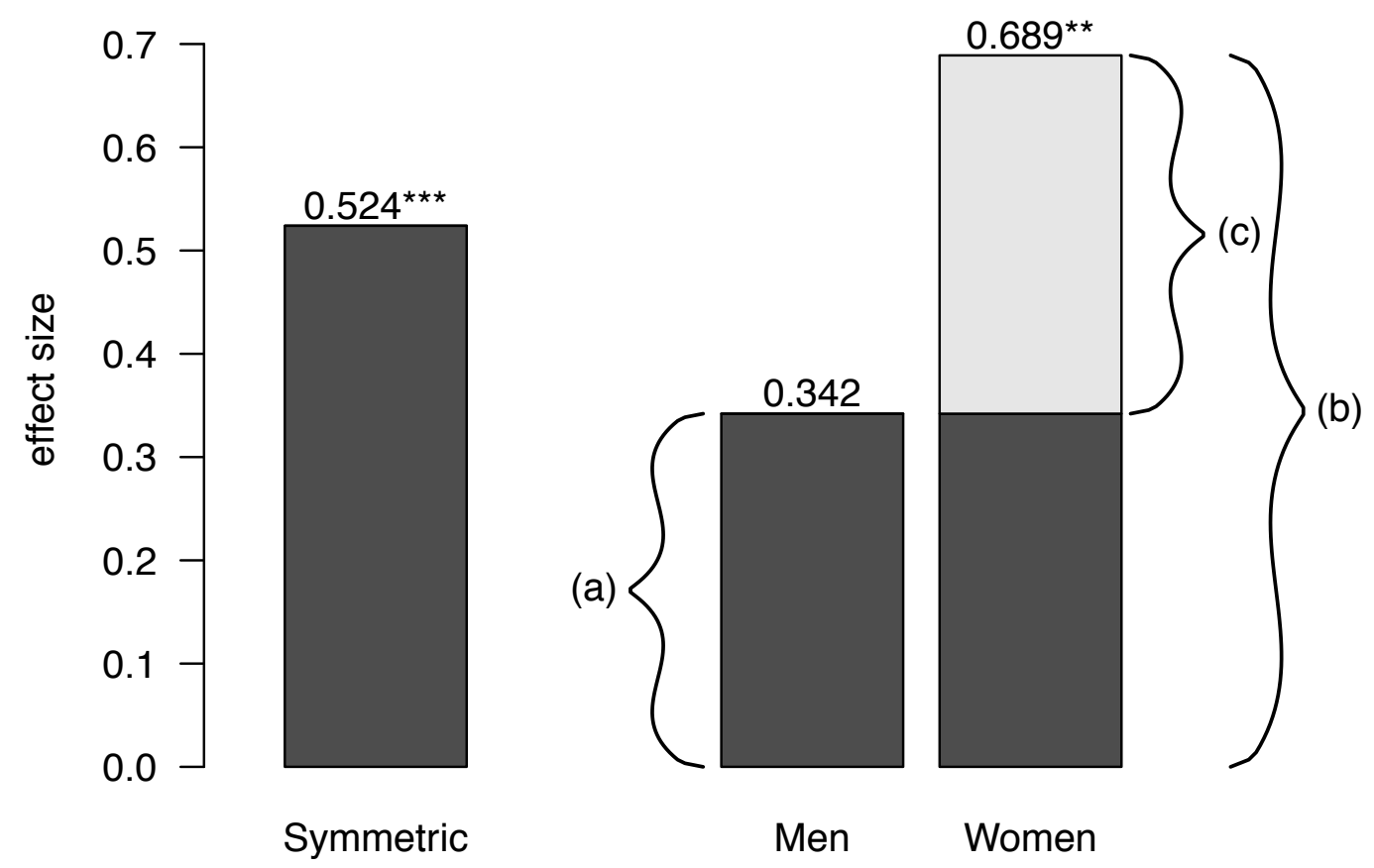

Figure 1. Different Ways to Compare the Gender-Stereotypical and Reverse-Stereotypical Beauty Exchange Effect, Based on Log-Linear Models. Component (a) is the beauty exchange effect for men (reverse-stereotypical), component (b) is the beauty exchange effect for women (gender-stereotypical), and component (c) is the difference in effects between (a) and (b).

${ }^{*} \mathrm{p}<.05 ; * * p<.01 ; * * * p<.001$ (two-tailed tests). 